\title{
Considerações Acerca da Poluição do Ar e Circulação de Veículos na Região Central de Curitiba/PR
}

\author{
Considerations on Air Pollution and Vehicle Traffic in the Central Zone of \\ Curitiba/PR
}

\begin{abstract}
Consideraciones acerca de la contaminación del aire y el movimiento de vehículos en la Región Central de Curitiba / PR
\end{abstract}

\author{
Francisco Jablinski Castelhano ${ }^{i}$
}

Recebido em 25/01/2017. Aceito em 08/05/2017.

\begin{abstract}
RESUMO: Este trabalho tratará da poluição atmosférica no município de Curitiba, Estado do Paraná, e sua relação com o volume de veículos na região central da mesma. Segundo dados da Prefeitura do Município (2016), os veículos são sua principal fonte de poluição, o que torna as regiões com tráfego mais intenso as piores neste quesito. Foram selecionados dados relativos a material particulado fino (PM10), Ozônio Troposférico $\left.\mathrm{O}_{3}\right)$ e Dióxido de Nitrogênio $\left(\mathrm{NO}_{2}\right)$, coletados pela estação de monitoramento da qualidade do ar do Instituto Ambiental do Paraná (IAP), localizada na Praça Ouvidor Pardinho, região central da capital para o ano de 2013. Tais dados foram cruzados com informações de trânsito referentes a volume de tráfego total, através de radares dispostos em vias no entorno da referida estação para o mesmo período. Foram organizados gráficos mostrando as oscilações em escalas mensais, semanais e diárias de ambas estas variáveis. Em escala mensal, a relação entre volume de veículos e poluição do ar não ficou suficientemente clara uma vez que nesta escala de análise, os fenômenos climáticos exercem maior influencia sobre a qualidade do ar, contudo observando a escala semanal e diária pode-se observar a influencia do amonte de veículos e dos picos de poluição.
\end{abstract}

Palavras-Chave: Poluição Atmosférica; Tráfego de Veículos; Curitiba.

\begin{abstract}
This work treats air pollution in the city of Curitiba, state of Paraná, and its relationship with the vehicle traffic volume in the center region of this city. According to data from the City hall (2016) the vehicles are the main source of air pollution, , what makes the regions of the city with the heaviest traffic the ones with the worst air quality. For this analysis, were selected Particulate Matter (PM 10), Tropospheric Ozon $\left(\mathrm{O}_{3}\right)$ and Nitrogen Dioxide $\left(\mathrm{NO}_{2}\right)$ data, collected at the air quality monitoring station located at the Ouvidor Pardinho Square, provided by the Environmental Institue of Paraná (IAP) at the central region of the city, for the year of 2013. These data were crossed with total traffic information collected at speedtraps located in streets nearby the station for the same period. Graphics were organized showing the oscillation in monthly, weekly and daily scale from both variables, revealing the existence of a relationship between then. At the monthly scale, the relationship between vehicle traffic and air pollution was not clear enough, once that, at this scale, the climate have a stronger influence on the air quality, in the other hand, observing the weekly and daily scale, it was possible to see the influence of the vehicles and the peaks of air pollution.
\end{abstract}

Key Words: Air Pollution; Vehicles Traffic; Curitiba

RESUMEN: Este articulo aborda la polucion atmosférica en la ciudad de Curitiba, estado de Paraná y sus relaciones con el volumen de veiulos en su region central. Segundo datos del Ayuntamiento de la ciudad (2016), los vehículos son su principal fuente de polucion atmosférica, haciendo con que las regiones com mayor trafego sean las piores en esto aspecto.Fueran seleccionados datos relativos a material particulado fino (PM10), Ozonio $\left(\mathrm{O}_{3}\right)$ e Dioxido de nitrogenio $\left(\mathrm{NO}_{2}\right)$ colectados por la estacion de monitoreo de la calidad del aire del Instituto Ambiental de Paraná (IAP), situado en la Plaza Ouvidor Pardinho, region central de la ciudad para el ano de 2013. Estos datos fueron relacionados 
con informaciones de trafico con el uso de radares de velocidad situados en calles en el entorno de la referida estacion para el mismo período. Fueron organizados gráficos que muestran las oscilaciones en escalas mensuales, semanales y diárias de las dos variables. En la escala mensual, la relacion entre los vehiculos y la polucion del aire no fue suficientemente clara, ya que, en esta escala de analisis los fenômenos climáticos tienen una mayor influencia sobre la calidad del aire, todavia, en las escalas semanal y diária se observo la influencia de los vehiculos en los picos de poluicion

Palabras-Clave: Polucion Atmosferica; Trafico de Vehiculos; Curitiba

\section{INTRODUÇÃO}

O conceito de poluição é trazido por Ayoade (1986) como a entrada de quaisquer substâncias em um dado meio, e que seja diferente de seus componentes naturais, a ponto de afeta-lo de forma danosa.

Sua origem difere-se entre antrópica e natural, assim polens, bactérias e erupções vulcânicas são exemplos de poluentes naturais, e principalmente a queima de combustíveis fósseis como a poluição de origem antrópica.

As principais consequências nos ambientes atmosféricos podem ser subdividas em três grandes grupos: estéticos, irritantes e tóxicos.

Os efeitos estéticos são aqueles classificados como alterações da aparência do ar que nos envolve e que afetam negativamente nossos sentidos, assim incluem-se a coloração do ar, fuligem, mau cheiro entre outros, portanto os menos danosos.

Os efeitos irritantes já causam certos desconfortos além da aparência, tais como ardência nos olhos e mucosas, e por fim, os efeitos tóxicos, classificados como consequências extremas a saúde em consequência de envenenamento por gases tóxicos, atingindo sistemas respiratórios, cardiovascular e nervoso a depender do poluente e do nível em que o mesmo se encontra. (BRANCO E MURGEL, 2012,p. 49).

Ayoade (1986) cita ainda que a intensidade da poluição atmosférica em determinado local tem duas variáveis principais: o índice de poluentes emitidos e o índice de dispersão e diluição de tais poluentes.

O estado da qualidade do ar de um dado sítio situa-se então como fruto da relação entre fatores espaciais e temporais distintos agindo sob uma dada localidade. É citado comumente a presença de áreas industriais e do tráfego massivo de veículos como grandes desencadeadores deste problema ambiental (DERISIO,2012; BRANCO E MURGEL,2004) e que tem em determinadas situações meteorológicas as situações mais propicias a concentração ou dispersão destas partículas (DANNI-OLIVEIRA, 2000).

Estes fatores desencadeadores supracitados estão intimamente relacionados com o modelo de sociedade a qual fazemos parte, tendo relação direta com o comportamento e modo de vida dos citadinos.

A utilização de veículos, já mencionado como um grande responsável pela má qualidade do ar está intimamente ligado a tal afirmação. O fato do carro, nas sociedades 
ocidentais ser objeto de status, vem em conjunto com os grandes números de veículos observados circulando nas cidades. Transportes alternativos e com menores índices de agressão a qualidade do ar, tais como bicicletas, transportes públicos ou mesmo caminhadas acabam por ser deixado de lado em função deste fator (STEG, 2005).

No caso de Curitiba a frota de carros saltou de 808.070 veículos registrados em 2003 para um numero de 1.429 .534 em 2013. Um crescimento de $76,9 \%$ em 10 anos, sendo que a cidade apresenta um dos mais altos índices de carros por habitante, o que certamente implica de maneira direta e indireta na qualidade do ar desta cidade. Em 2003, a relação era 0,48 veículos por habitante de Curitiba, já em 2013 saltou para 0,77 (DENATRAN,2016).

Reforçando o papel do carro na má qualidade do ar em Curitiba, em relatório divulgado em 2016, contabilizou-se que, $72 \%$ das emissões de gases de efeito estufa na cidade provinham de veículos automotores, cabendo a fontes fixas, as quais entram principalmente atividades industriais apenas $13 \%$, e o restante provindos de gestão de resíduos (PREFEITURA DE CURITIBA, 2016).

A fim de se aprofundar na dinâmica da qualidade do ar, este estudo tem como objetivo observar o comportamento dos poluentes Ozônio Troposférico $\left(\mathrm{O}_{3}\right)$, PM 10 e Dióxido de Nitrogênio $\left(\mathrm{NO}_{2}\right)$ na região central da cidade de Curitiba e suas relações com o tráfego de veículos na região, apontado pelo Instituto Ambiental do Paraná (IAP, 2013) como um dos grandes responsáveis pela má qualidade do ar nesta região em especifico.

Associações entre o aumento no número de hospitalizações e mortes por problemas respiratórios e cardiovasculares e aumentos nos níveis de $\mathrm{O}_{3}, \mathrm{PM} 10$ e $\mathrm{NO}_{2}$ confirmando tal relação são várias e atestam a necessidade de se aprofundar dita temática (BELL ET. AL, 2004, DANNI-OLIVEIRA, 2009).

A qualidade do ar do Aglomerado Urbano de Curitiba (AUC) é monitorada através de estações medidoras de qualidade do ar, localizadas nos municípios de Curitiba e Araucária (Figura 01).

Tal monitoramento teve início no ano de1985, com a instalação de uma estação de monitoramento na Santa Casa de Curitiba, localizada na Praça Rui Barbosa, região central da cidade, e outras três no município de Araucária. Atualmente, a rede conta com um total de oito estações automáticas e mensalmente boletins com os resultados das coletas são disponibilizados através do sítio eletrônico do órgão para a população. 
Figura 01: Localização das Estações da Rede de Monitoramento da Qualidade do Ar

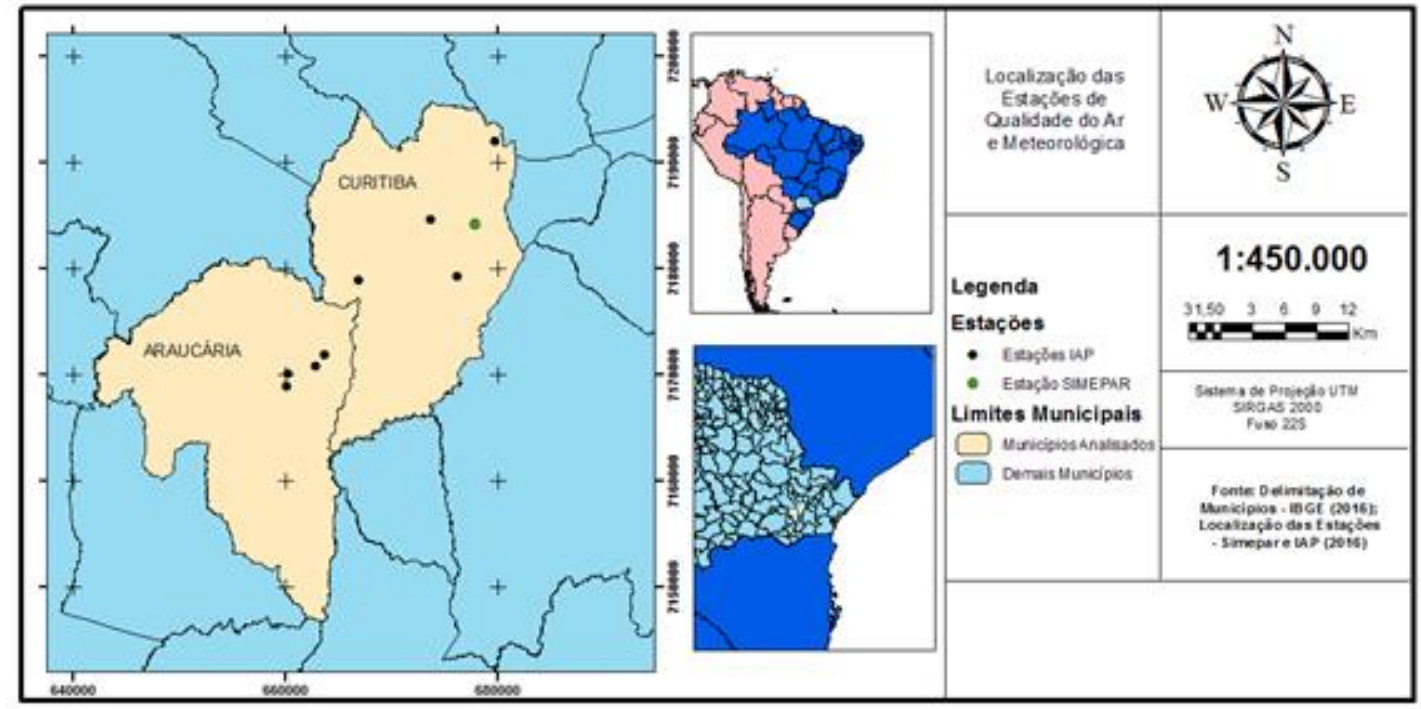

\section{DESENVOLVIMENTO}

\section{Procedimentos Metodológicos}

Para a execução deste trabalho, primeiramente foram coletados dados em escala horária de Dióxido de Nitrogênio, Ozônio Troposférico e PM 10 da estação oficial de Monitoramento da qualidade do ar alocada na Praça Ouvidor Pardinho para o ano de 2013.

Tais dados foram tratados e organizados através do software Excel e foram analisados em conjunto com os dados de volume total de tráfego de veículos em pontos próximos a esta estação. Estes dados foram coletados junto a radares de velocidade localizados nas Rua 24 de Maio, Rua Alferes Poli, Avenida Marechal Floriano Peixoto e Avenida Silva Jardim indicados pelos números 1 a 4 na figura 2 , respectivamente.

Para a comparação de dados de circulação de veículos com poluição atmosférica, os mesmos foram organizados em escalas temporais equivalentes. Assim, foram gerados valores médios de poluição por mês, dia da semana e hora do dia. E igualmente valor médio de carros/dia na escala mensal e por dias da semana e carro/hora em 24 horas.

A análise comparativa entre as duas variáveis se deu através de cálculos de correlação e análise gráfica, ambas geradas através dos softwares Excel e RStudio

A figura 3 apresenta os resultados da análise em escala mensal. Os quatro radares revelaram o mês de Junho como aquele em que menos há circulação de veículos, com grandes diferenças quando comparados aos outros meses. 
Figura 02: Localização dos Radares e Estação de Monitoramento da Qualidade do $\mathrm{Ar}$

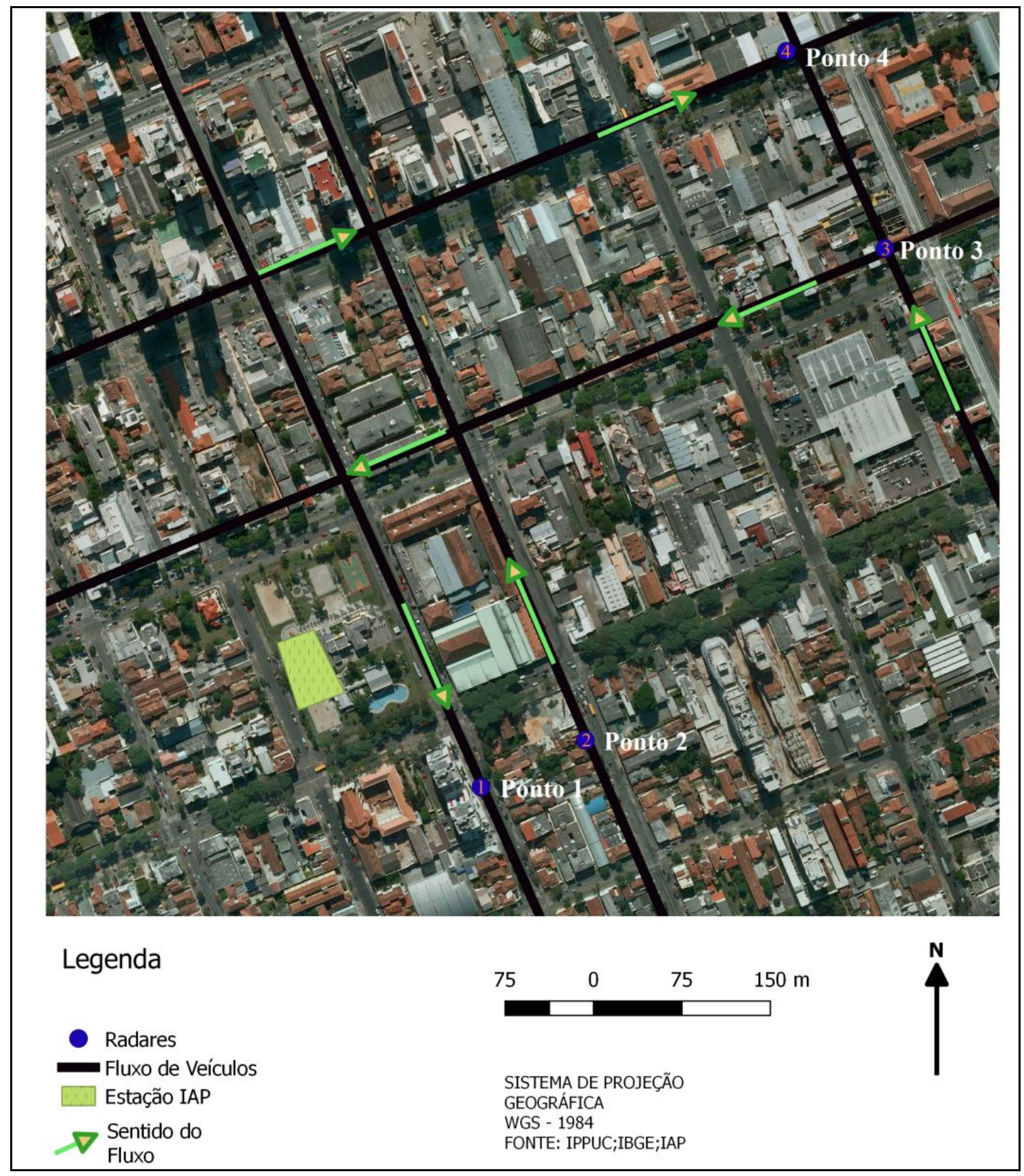

\section{Resultados e Discussões}

Pode-se perceber que de maneira geral, a circulação de veículos cresce dos meses de janeiro a abril, a partir de quando se inicia sua queda, culminando com o mês de junho para em seguida voltar a subir até setembro/outubro, quando novamente volta a cair. Os períodos de férias escolares (Dezembro, Janeiro, Fevereiro e Junho) exerceram grande influência no número de veículos circulando pelos locais aqui estudados. 
Figura 03: Circulação Média Mensal de Veículos (Carros/dia) e Média Mensal de $\mathrm{O}_{3}, \mathrm{NO}_{2}$ e PM10 $\left(\mu \mathrm{g} / \mathrm{m}^{3}\right)$

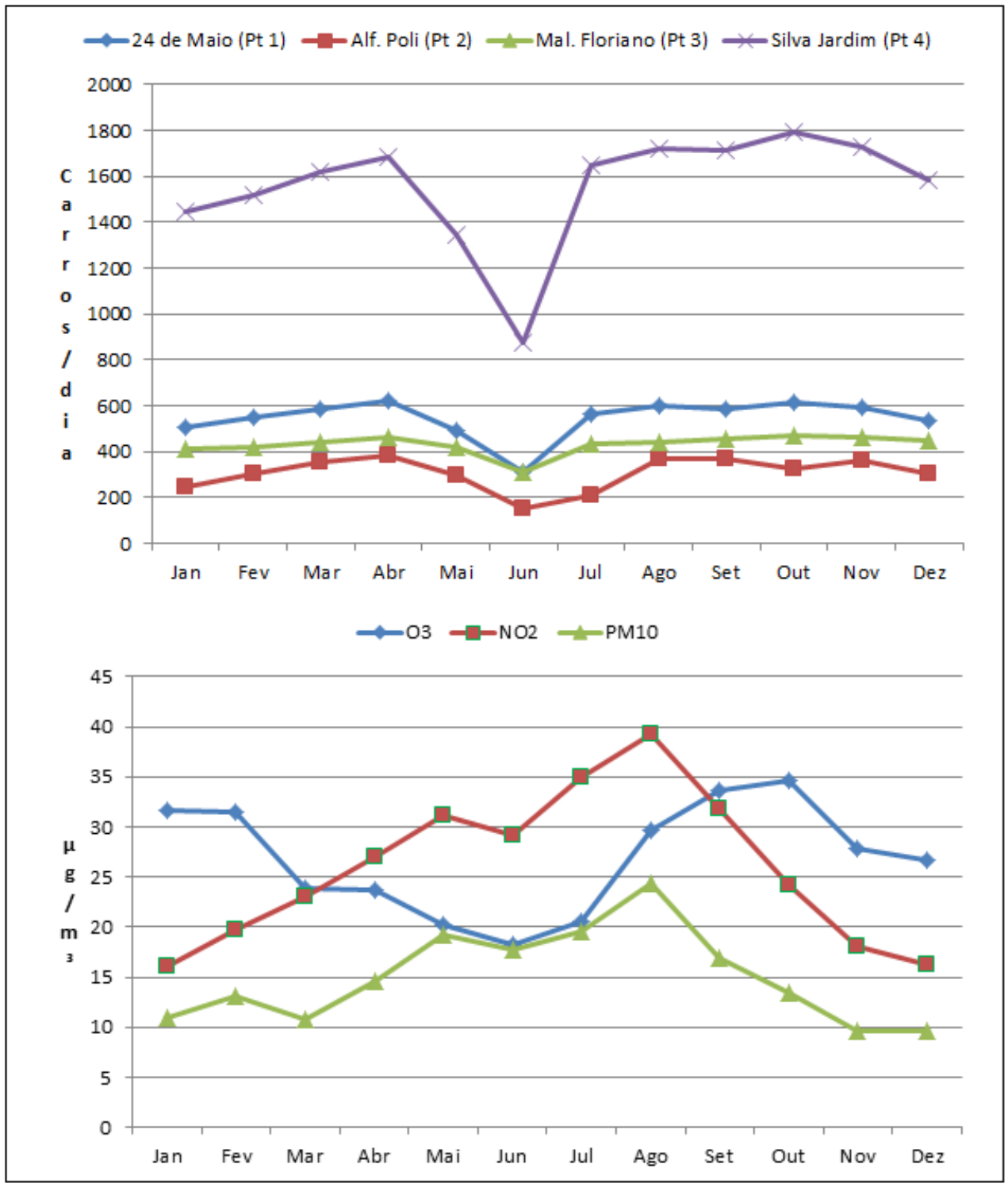

Fonte: IAP, e IPPUC; Org.: Autor (2016)

Comparando tais dados com os valores médios de poluição por mês, podem-se apontar algumas considerações. Danni-Oliveira (2000) e Mendonça e Castelhano (2016) apontam os períodos de inverno para Curitiba como aqueles em que a situação atmosférica é mais propícia para o acúmulo de Material Particulado e Dióxido de Nitrogênio, devido a esta ser a época mais seca do ano e em que predomina a estabilidade do tempo atmosférico.

Mendonça e Castelhano (2016) apontam também o período de inverno como aquele em que menos se registra Ozônio troposférico na cidade, devido à necessidade de radiação solar para a formação química deste composto.

Schirmer e Lisboa (2008) indicam que o dióxido de Nitrogênio é altamente sensível à luz e radiação, sofrendo o processo de fotólise que tem como resultado a dissociação da 
molécula de $\mathrm{NO}_{2}$ em $\mathrm{NO}$ e um oxigênio atômico, que tem a possibilidade de reagir com o $\mathrm{O} 2$ e compostos orgânicos voláteis (COV), formando o $\mathrm{O}_{3}$, outro poluente mais prejudicial.

Segundo Seinfeld e Pandis (2006) para a formação do $\mathrm{O}_{3}$ é necessário um dado equilíbrio entre Nox e VOC's, assim, altos níveis de NOx não representam necessariamente altos níveis de $\mathrm{O}_{3}$.

Aspectos meteorológicos explicam em grande parte a formação da dinâmica aqui vista, quando os meses de maio a agosto apresentam-se como o período de maior concentração de $\mathrm{NO}_{2}$ e PM10 na capital paranaense.

Todavia, analisando em conjunto as informações referentes ao tráfego, sugere-se que o baixo número de veículos em circulação registrado no mês de junho pode ser o responsável pela queda nos valores médios de poluição observados no mesmo mês para os três poluentes quando comparados aos meses próximos.

O PM10 e $\mathrm{NO}_{2}$ em especial, se encontram em períodos meteorologicamente propícios ao seu acúmulo, dado que, os níveis de chuva são mais baixos e o ar mais frio e denso, em função de sua maior proximidade a superfície auxilia a não dispersão destes compostos, contudo, no mês de junho, constataram-se níveis abaixo até de maio e julho.

No caso do Ozônio, o mês de junho também apresentou valores mais baixos que o anterior e o posterior, apesar de as condições meteorológicas destes períodos serem semelhantes entre si.

A relação entre o número de veículos e a poluição torna-se mais clara à medida que se afunila a escala conforme se pode observar na figura 4 , em que se apresentam os valores médios por dia da semana.

Em todos os radares constatou-se uma notável diferença entre o amonte de veículos que circula de segunda a sexta para o total nos sábados e domingos. A título de exemplo, o radar localizado na Avenida Silva Jardim, uma via com cinco faixas de rolagem apontou uma média de 1778 veículos circulando nas sextas-feiras enquanto que aos domingos este valor cai para 1064.

Esta diferença é sentida quando analisamos os valores de $\mathrm{PM}_{10}$ e $\mathrm{NO}_{2}$ por dia da semana. O primeiro chega a apresentar um valor médio de $28,1 \mu \mathrm{g} / \mathrm{m}^{3}$ durante as quartasfeiras e quintas-feiras, enquanto que aos domingos o mesmo cai para $19,5 \mu \mathrm{g} / \mathrm{m}^{3}$.

O PM10 igualmente apresenta seu ápice às quintas-feiras quando chega a ter um valor médio de $16,5 \mu \mathrm{g} / \mathrm{m}^{3}$, já aos domingos cai para $11,8 \mu \mathrm{g} / \mathrm{m}^{3}$. A exceção neste caso esta no ozônio troposférico que apresenta uma dinâmica totalmente oposta, com seus maiores valores sendo registrados em finais de semana. 
Segundo Dallarosa (2005) é normal encontrar as maiores concentrações de Ozônio Troposférico em locais distantes a sua fonte emissoras de $\mathrm{NOx}$ e $\mathrm{NO}_{2}$ dado que, existe um dado tempo de reação e mistura para a produção deste poluente.

Figura 04: Circulação Média Diária/Semanal de Veículos (Carros/dia) e Média Diária/Semanal de $\mathrm{O}_{3}$, $\mathrm{NO}_{2}$ e PM10 $\left(\mu \mathrm{g} / \mathrm{m}^{3}\right)$

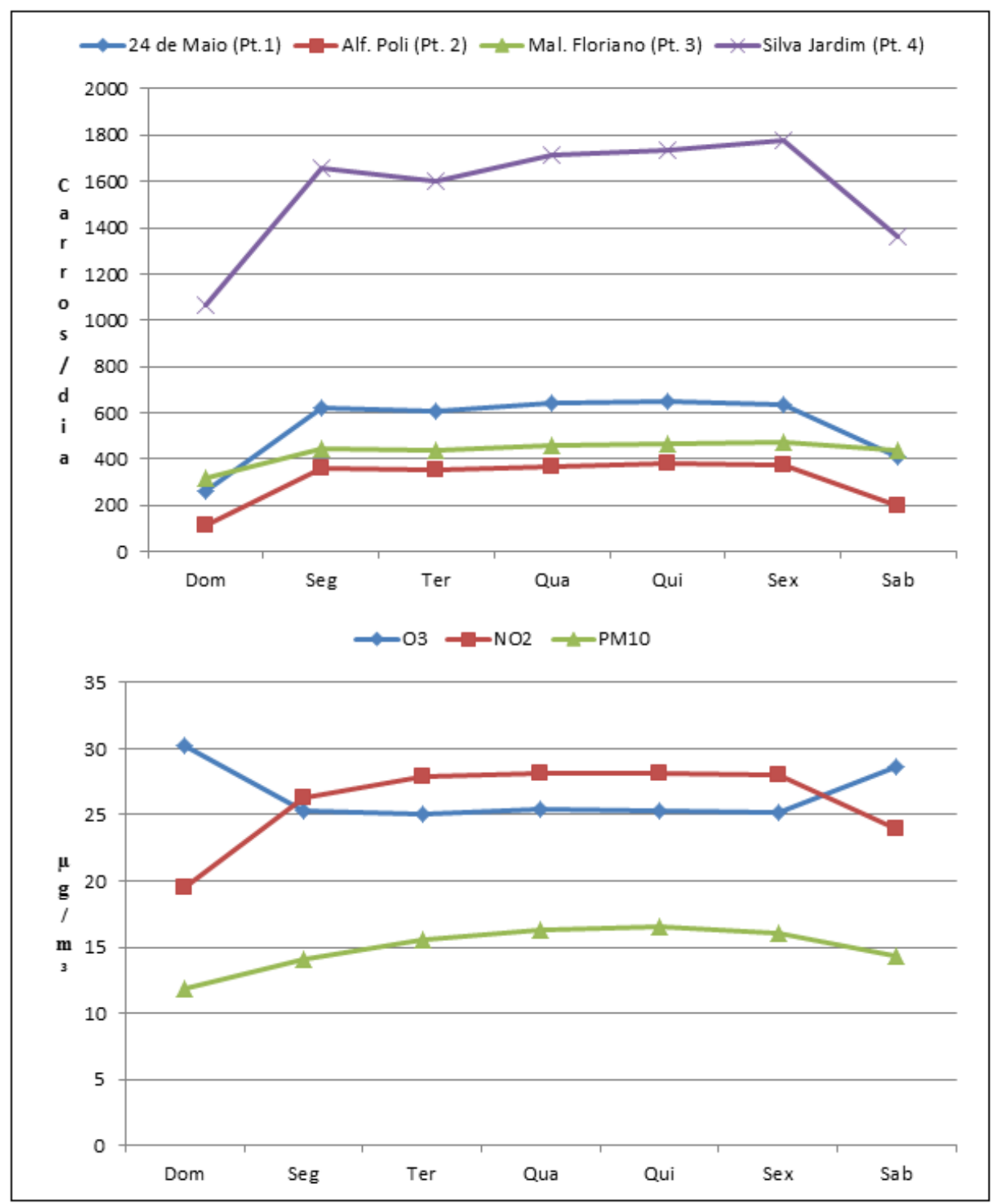

Fonte: IAP, e IPPUC; Org.: Autor (2016)

Passando para a análise de dados em escala diária pode-se observar que os quatro radares tiveram algumas características semelhantes (Figura 5). Em todos se observa o período de meia-noite às $4 \mathrm{~h}$ como o de mais baixa circulação. A partir deste último horário observa-se uma crescente culminando com o pico de trânsito matutino àss $8 \mathrm{~h}$. 
Interessante salientar que no ponto 3, alocado na Av. Marechal Floriano, constatou-se uma manutenção de valores altos até as 18h, a partir de quando passam a diminuir gradativamente.

Figura 05: Circulação Média Horária/Diária de Veículos (Carros/hora) e Média horária/diária de $\mathrm{O}_{3}$, $\mathrm{NO}_{2}$ e PM10 $\left(\mu \mathrm{g} / \mathrm{m}^{3}\right)$

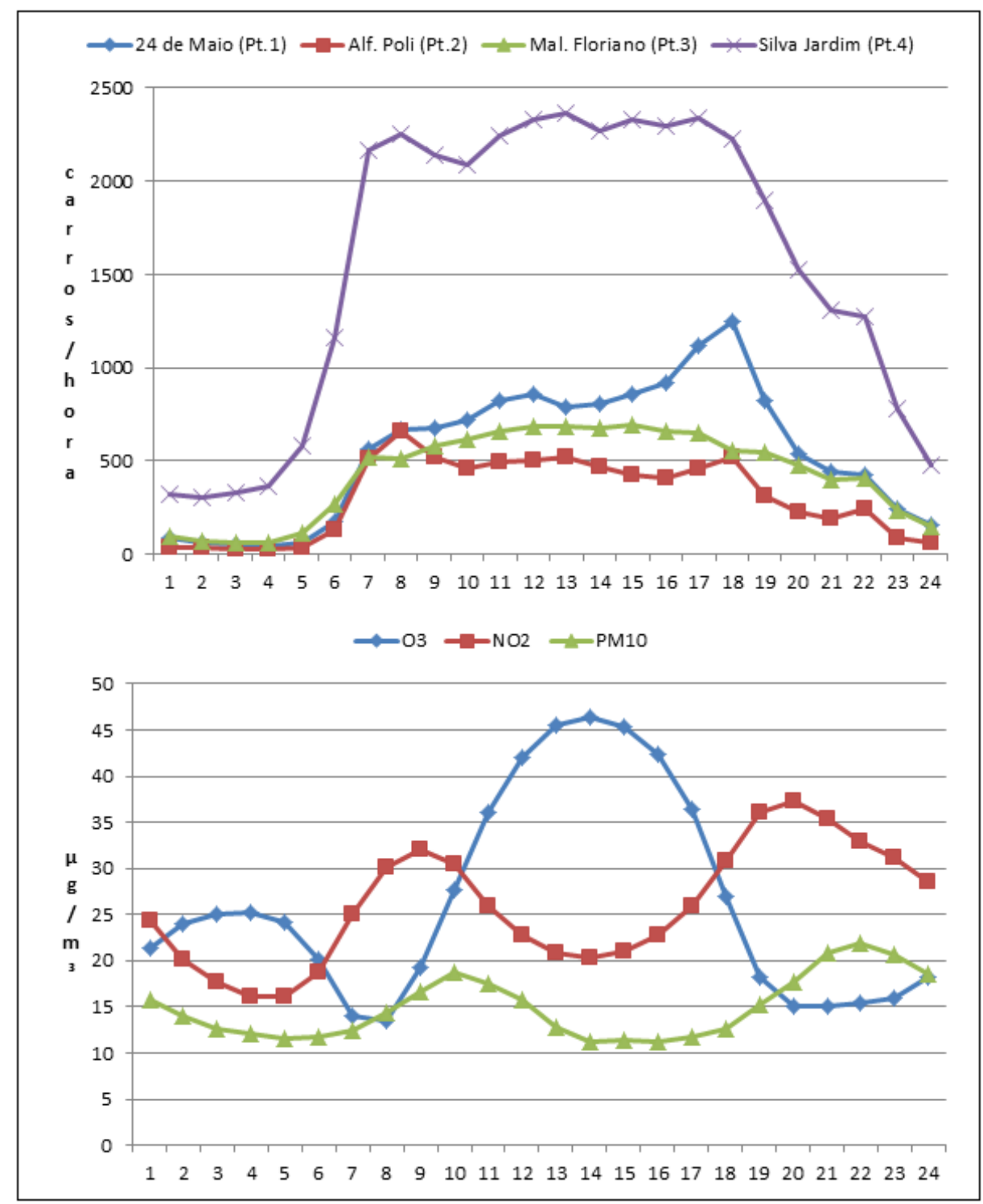

Fonte: IAP, e IPPUC; Org.: Autor (2016)

O Ponto 1 na Avenida 24 de Maio tem uma dinâmica próxima, com aumentos gradativos a partir das $8 \mathrm{~h}$ e com um pico pronunciado as $18 \mathrm{~h}$.

Já nos pontos 4 (Avenida Silva jardim) e 2 (Rua Alferes Poli), após este primeiro pico, observou-se uma ligeira queda no número de veículos, voltando a subir no horário das $13 \mathrm{~h}$. A partir deste horário, observou-se um novo pico às $18 \mathrm{~h}$ a partir de quando os valores voltam a cair. Em ambos estes radares, deflagrou-se um valor maior de carros às $18 \mathrm{~h}$ 
quando comparados as $8 \mathrm{~h}$, o que também ocorre no ponto 3. Já no ponto 2 o maior volume de veículos é registrado no pico matutino.

Passando a análise para a oscilação de poluição, nota-se que, novamente os valores de Ozônio troposférico destoam dos demais. O poluente apresentou dois picos, o primeiro, de menor valor às $4 \mathrm{~h}$ e o segundo mais pronunciado às $14 \mathrm{~h}$.

Ambos estes horários não tiveram volumes de tráfego que justificassem tais valores, pelo contrário, foram momentos em que a circulação de veículos encontra-se baixa quando comparados a demais momentos do dia. Tal fato é esperado dado ao fato deste poluente ser secundário.

Observou-se também uma relação inversa entre níveis de $\mathrm{O}_{3}$ e $\mathrm{NO}_{2}$ de maneira direta. Os horários de maiores níveis de $\mathrm{NO}_{2}$ se sucederam em momentos de baixa concentração de $\mathrm{O}_{3}$ e o inverso se sucedeu, com os picos de $\mathrm{O}_{3}$ ocorrendo nas horas de menor concentração de $\mathrm{NO}_{2}$.

Tal fato é esperado e foi registrado em estudo semelhante ocorrido em Barcelona por Filella e Peñuelas (2006). Neste estudo, os autores apontaram a relação química entre NO2 e outros óxidos de nitrogênio e o ozônio troposférico, como justificativa para tal relação. Portanto, o tráfego acaba tendo uma relação indireta com a formação de dito poluente.

O Dióxido de Nitrogênio e o PM10 tiveram oscilações inerentes aos valores de tráfego. O primeiro apresentou seu pico matutino às $9 \mathrm{~h}$ e noturno às $20 \mathrm{~h}$, enquanto que o PM10 teve seus picos mais tarde, às $10 \mathrm{~h}$ e $22 \mathrm{~h}$ respectivamente sendo que, os picos noturnos apresentaram valores médios superiores que os matutinos, consequência de um maior volume de carros neste período.

Observou-se, portanto, um delay entre os picos de PM10 e $\mathrm{NO}_{2}$ apesar de ambos proverem da mesma fonte. Tal diferença também foi observada em estudo semelhante realizado na região da Andaluzia no sul da Espanha, para os anos de 2003 a 2008. Segundo Adame et al (2014), tal diferença se sucede pelos índices de difusão e diluição diferentes destes poluentes.

\section{CONSIDERAÇÕES FINAIS}

As oscilações nos valores dos poluentes analisados obedecem a temporalidades definidas pelos índices de emissão e condições meteorológicas vigentes. Esta relação se dá de distintas formas a depender da escala temporal de análise e do ponto a ser estudado.

A região central de Curitiba tem na circulação de veículos sua grande fonte emissora, influindo diretamente nos níveis dos poluentes primários $\left(\mathrm{PM} 10\right.$ e $\left.\mathrm{NO}_{2}\right)$. Tal fato se constata com mais destaque nas análises propostas nas figuras 4 e 5, onde se constata uma relação 
muito próxima entre estas duas variáveis. No caso da figura 4, se observa um aumento nos níveis de $\mathrm{PM} 10$ e $\mathrm{NO}_{2}$ ao longo da semana e um declínio aos finais de semana. Já na figura 5 , observa-se uma relação direta entre os picos de tráfego e os picos destes poluentes em dois momentos do dia.

Observando o caso do ozônio troposférico, constatou-se que o mesmo possui uma relação indireta com a circulação de veículos. Tal fato se deve a característica secundaria deste poluente e a necessidade de um equilíbrio entre $\mathrm{O} \mathrm{NO}_{2}$, COV's e radiação solar para sua formação. Assim, observou-se o crescimento deste poluente sempre em momentos em que o $\mathrm{NO}_{2}$ encontrava-se baixo, demonstrando a relação direta entre os volumes de ambos.

O aprofundamento de estudos climáticos poderia estabelecer uma maior gama de detalhes e complementar este estudo, garantindo maior eficácia nas politicas públicas que envolvam tal temática.

Outro ponto a ser levantado está no planejamento urbano de Curitiba, que se mostra como deficitário quando analisado sob a ótica da qualidade do ar. Tal afirmação se embasa no cenário de concentração de veículos e de trânsito em pequenos espaços da cidade, na ausência de praças e espaços verdes e no adensamento de construções nestes mesmos espaços. Apesar de todos estes fatores, a simples redução de carros circulando já seria suficiente para amenizar os problemas relacionados à qualidade do ar no na região aqui estudada.

Pensando no lado cultural/social, observam-se alguns fatos enraizados na população brasileira em geral e que contribuem diretamente para a má qualidade do ar, deflagradas ao longo deste trabalho. Primeiramente a necessidade do carro individual, o status trazido pela posse de um carro supera os problemas causados por seu uso. O "porém" se encontra a partir do momento em que deixar o carro em casa e utilizar outros meios de transporte tais como o transporte coletivo, bicicletas ou carona se tornam um verdadeiro ato de coragem, dada a falta de estrutura para tal fato.

Para contornar tal processo, é necessária mais do que apenas boa vontade dos usuários de carro e consciência de seu ato, mas também incentivos por parte do poder público para que estes meios de transporte sejam tão atrativos quanto o próprio carro.

Há de se pensar também no incentivo a novas tecnologias e rendimento de combustíveis. A utilização de novas fontes de energia com menor carga emissora

\section{REFERÊNCIAS BIBLIOGRÁFICAS}

ADAME, J.A, HERNANDÉZ-CEBALLOS,M.A, SORRIBAS, M., DE LA MORENA, A.L.B.A., Weekend-Weekday Effect Assessment for O3, NOx, CO and PM10 in Andalusia, Spain (2003-2008), Aerosol and Air Quality Research,v. 14,p. 1862-1874, 2014. 
AYOADE, J.O. Introdução a Climatologia para os Trópicos, São Paulo, Editora Difel,1986.

BELL, M.L, MCDERMOTT,A. ZEGGER, S.L, SAMET, J.M. e DOMINICI,F. Ozone and Shortterm Mortality in 95 US Urban Communities, 1987-2000, Journal of the American Medical Association, n. 19, v. 292, p. 2372-2378, 2004

BRANCO, S.M e MURGEL, E. Poluição do Ar, São Paulo Editora Moderna, 2004.

CASTELHANO, F. J. ; MENDONÇA, F.,Climate, Urban Planning and Tropospheric Ozone in Curitiba (Brazil): Risks to the Populations Health, In: ICUR PROCEEDINGS. 2016.Lisboa, Edit Univ Lisboa v. 1. p. 1-8.

DANNI-OLIVEIRA, I.M, A cidade de Curitiba e a Poluição do ar. 2000 Tese de doutorado, Departamento de Geografia, USP, São Paulo

DANNI-OLIVEIRA, I.M,Poluição do Ar como Causa de Morbidade e Mortalidade da População Urbana, Ra'ega, Curitiba, v. 15, p. 111-124, 2009.

DALLAROSA, J.B., Estudo Da Formação e Dispersão De Ozônio Troposférico em Áreas de Atividade de Processamento de Carvão Aplicando Modelos Numéricos, 2005, Dissertação de Mestrado, UFRGS, Porto Alegre.

DENATRAN, Frota de veículos por Tipo e Município, 2017, Disponível em: < http://www.detran.pr.gov.br/modules/catasg/servicos-detalhes.php?tema=detran\&id=469>,

Acessado em : 10 nov.2016

DERISIO, J.C. Introdução ao Controle de Poluição Ambiental, São Paulo, Ed. Oficina de Textos, 2012.

FILELLA,I. e PEÑUELAS, J., Daily, weekly and seasonal relationships among VOCs, NOx and $\mathrm{O} 3$ in a semi-urban area near Barcelona, Journal of Atmospheric Chemistry, V. 54, N. 2, p. 189-201, 2006.

IAP, Relatório Anual da Qualidade do Ar na Região Metropolitana de Curitiba Ano de 2013, Curitiba, 2013.

MENDONÇA, F. A. ; CASTELHANO, F. J. . Les Types de Temps et la Qualite de L'Air a Curitiba (Bresil),In: COLLOQUE DE L'ASSOCIATION INTERNATIONALE DE CLIMATOLOGIE, XXIX, 2016, Besançon, v. 1. p. 69-74.

.PREFEITURA DE CURITIBA, Curitiba Ações Estratégicas: Clima e Resiliência, Curitiba, 2016.

SCHIRMER, W.N.; LISBOA, H.M. Química da Troposfera: constituintes naturais, poluentes e suas reações. Tecnológica Santa Cruz do Sul, v. 12 n. 2, p. 37-46, 2008.

SEINFELD, J.e PANDIS, S., Atmospheric Chemistry and Physics: from air pollution to climate change, Wiley-interscience, 2006.

STEG, L.Car use: lust and must. Instrumental, symbolic and affective motives for car use, Transportation Research Part A: Policy and Practice, V.39, p. 147-162, 2005.

' Geografo, Bacharel e Licenciado em Geografia, Universidade Federal do Paraná, Doutorando do Programa de Pós-Graduação em Geografia, Av. Cel Francisco H. dos Santos, S/N, Jardim das Américas, Curitiba, Paraná, 81530-900, fjcastelhano@gmail.com 